\title{
Marketing tradition-bound products through storytelling: a case study of a Japanese sake brewery
}

\author{
Yong-sook Lee $\cdot$ Woo-jin Shin
}

Received: 10 November 2012/ Accepted: 13 December 2013/Published online: 8 January 2014

(C) The Author(s) 2014. This article is published with open access at Springerlink.com

\begin{abstract}
This study examines storytelling as a marketing strategy to revitalize the tradition-bound Japanese sake industry. The case analyzed in this study is Kida Brewery located in Nara Prefecture. This research focuses on sake masters (called "Toji"), who have laid the foundation for the globalization of sake and their indomitable craftsmanship. This study provides strategic insights on developing new marketing and production approaches which can help revitalize the sake industry in Japan. Kida Brewery has almost 300 years of history and family tradition as a sake brewery. The storytelling of its tradition and production methods can be an innovative way to engage customers to achieve their loyalty. Also this study will provide a new opportunity for traditional Japanese sake masters to learn new strategies to cope with challenges such as global supply chain, succession of the master culture and family business, and technology adoption.
\end{abstract}

Keywords Storytelling - Master culture and tradition .

Customer experience in tourism . The sake industry

\section{Introduction}

Alcoholic drinks represent a country's culture. Most cultures have their own myths or traditions related to alcohol. This is the reason why alcohol is consumed for all kinds of special human events, including celebrations and funerals, to enhance people's joy or sharing sorrows. A country's traditional alcoholic drinks, such as

\footnotetext{
Y. Lee $(\bowtie)$

Osaka University of Economics, Osaka, Japan

e-mail: leeyong58@gmail.com

W. Shin

Hongik University, Seoul, Korea

e-mail: ujin8396@daum.net
} 
Japanese sake, have been handed down throughout the history of the country. The representative traditional alcoholic drinks, such as Chinese maoutai, Korean rice wine, German beer, Scotch whisky, French wine, North European vodka, Cuban rum, Mexico's tequila and the like, are recognized as food, rather than alcoholic beverages (Korea Agro-Fisheries and Food Trade Corporation 2006). Alcoholic drinks cannot be separated from the food culture in countries where grains are the staple food. Countries using similar food ingredients have similar alcoholic beverages, clothing and shelter (Satoshi 2013). In this regard, the cultural establishment of humankind is closely related to alcohol (Lee 2011). Alcoholic beverages have been recognized as important cultural products as they contain many stories, traditions and histories. Businesses related to alcoholic drinks have been developed into an independent industry with high cultural and economic value (Kim 2010; Kim and Jeong 2010). Thus, Japanese sake can integrate products and services, sake and story-imbedded services, as a marketing strategy for customer servitization, especially for tourism (Kim and Yoon 2012).

Storytelling and word-of-mouth have been the characteristics of human history (Patterson and Brown 2005). These days, storytelling has been widely used as a means for content marketing of brands in many countries (Pulizzi 2012). However, there has been no study on storytelling regarding alcoholic drinks. As there is no precedent study on storytelling as a means to market Japanese sake, this study explores the story of Kida Brewery in Nara Prefecture, Japan. The researchers had a series of intensive interviews with the 8th and 9th sake masters of Kida Brewery, in addition to the examination of old documents and actual observations of the production processes/facilities, to prepare for this study.

Quality of sake is determined by various factors including smell, taste, color, and the type of sake. No matter how good the brewery industry is and how long the tradition is, the value of sake is hard to publicize without a system to deliver the story. Against this backdrop, this study intends to share the story of Kida Brewery by analyzing and comparing it with other breweries.

The success of sake is attributed to craftsmanship of Toji (sake master) for hundreds of years, systematic marketing strategies, and improved quality and standardization policies of the central government, local governments, and breweries themselves. Consideration of these factors is essential to study the secret of sake's success and its economic significance. In addition, this research could help improve the current sake industry in Japan. Kida Brewery has produced sake since 1718. The skills of masters who produced alcohol in Buddhist temples in the Edo period (1603-1867) in Japan have been handed down to today's sake masters.

This study focuses on the current state of the Japanese sake industry, including the manufacturing process, economic perspective, comparison between the sake industry and other brewery industries, and a focused case study of Kida Brewery. This study also presents an analysis of restrictions placed on and ways to improve the Japanese sake industry. The rest of the paper is organized as follows. Section 2 presents the theoretical background including the current state of the Japanese sake market, history of Kida Brewery, and storytelling as a marketing strategy. In Sect. 3, the research method used is described. Section 4 discusses the results of the study. 
In Sect. 5, this study concludes with a summary of major findings, limitations, and future research needs.

\section{Theoretical background}

\subsection{The current state of the Japanese sake market}

Sake, which is known as the Japanese spirit, is a part of the history of Japan. People began drinking sake around 400 A.D. History, culture and Sakagura (sake brewery) in Japan have changed over time. As is the case with other liquors, the Japanese sake market has been declining. Currently, the alcohol market value in Japan is about 5.3 trillion yen ( $\$ 5.3$ billion) where sake accounts for $15 \%$ or about 850 billion yen. Japan has bundled sake with sushi which has become a global food. The sake fever in the US, Europe, and Asian countries became possible due to many celebrities who are sake manias. As such, sake has become a global drink, going beyond a traditional alcoholic beverage of Japan.

The Japanese Ministry of Agriculture, Forestry and Fisheries and the Ministry of Foreign Affairs have utilized sake as a strategic product when they implemented the "Try Japan's Good Food Project". They developed a new type of rice dedicated to making sake to improve quality and eased regulations to lower entry barriers for small and medium-sized businesses. Recently the Japanese government designated sake as a cultural bridge into the twenty-first century to establish the "Enjoy Japanese Kokushu Project". Market exploration and expansion to improve awareness of sake and to promote export through global marketing represent important initiatives for the Japanese sake industry. In fact, the Japanese Brewery Association is making great efforts to revitalize the sake market. In 1996 the Japanese Alcohol Export Organization was established under the sponsorship of the Japanese Alcohol Service Research Association and Brewery Masters Association. The organization created an online site to introduce various sake products so that customers can search for their preferred products.

\subsection{History of Kida sake brewery}

In the Toyotomi era (1536-1598), Buddhism flourished resulting in a large number of temples. Kida Brewery began to make alcohol for memorial ceremonies at temples. At that time, Nara Prefecture included four areas: Yanagijawa, Takadori, Koizmi, and Ota. Kida Brewery is located in Takadori.

Kida Brewery is a well-known sake maker (Sakagura) which started its business in 1718, when the 8th general, Tokugawa Yoshimune, ruled the area. The first generation Kida began to sell sake and soy sauce, but the soy sauce business continued for only three generations. Initially, the production volume of sake was around 200 gok of rice ( 1 gok amounts to $30,000 \times 180 \mathrm{~L}$ bottle). In the Edo era, where Kida Brewery had a sake business for four generations, there were about 300 breweries in the area. From the 5th to 8th generation, the production volume was 
about 500 gok. As the Second World War occurred, the Japanese government ordered sake production reduced as rice was in short supply. The number of breweries shrank from 300 to 80 at that time. Breweries with small production volume or those with illegal sales activities and false tax filers were ordered to shutdown their business.

Fortunately, Kida Brewery has continued its business for 295 years without experiencing business closure or suspension because of its integrity. During the 7th Kida generation, when sake production was liberalized, it produced about 1,800 gok. During the 8th Kida generation, the sales volume was further reduced as the number of breweries decreased again from 80 to 24 . The reason for the reduced sales was due to the introduction of other types of alcohol, reduced alcohol consumption among young people, and control of driving under the influence with the increased number of cars.

Mr. Kazuyoshi, the 8th Kida master was born in 1941 and he is the father-in-law of the 9th Kida master, Mr. Hidoshi. The master in family business in Japan usually takes the family name. The first master's name was Kida Rihe and the name of 9th master is Kida Hidoshi. When the 8th master passes away, the name of the 9th master will be changed to Kida Rihe.

There are many well-known sound breweries in Japan with 200-300 years of history, including Umeda Brewery with 400 years of history in Nara Prefecture. For 80 years, Nara was the first capital of Japan, where Buddhism was imported from the Korean Peninsula, to be transformed into Asuka culture. In particular, Buddhism flourished during the Muromachi era having a large number of Buddhist temples and rites where monks made alcohol out of rice for religious rites. The first mold that made sake fermented from rice was found at Shorakuji temple around 992 A.D.

There were 86 monks who were making alcohol in Shorakuji temple. The number of monks increased to 120 and the temple became known for the alcohol made by monks. Based on the experience of making alcohol in this temple, the three-stage fermentation production method, which generated rice wine starter and fermentation fungi, and heat processing to prevent alcohol from going bad laid the foundation for the modern brewing method. This was a very innovative method representing the Muromachi era and included in the old Japanese data called "Koshushinitki" and "Dogashujogi" of the early Edo era. This historical background made Shorakuji in Nara Prefecture the birth place of sake.

The 9th Kida master Kida Hidoshi is 42 years old. The 8th master Kida Kazuyoshi has only daughters and thus his son-in-law Hidoshi succeeded the family business. In Japan, if a master has only daughters, a son-in-law changes his family name to continue his wife's family business.

Kida Hidoshi was born as the first son of a brewery family in Hukui Prefecture and graduated from the Fermentation Department of Tokyo Agricultural University. After graduation, he worked at the Japanese Brewing Research Center where he met his wife who visited the center for training. Hidoshi's family closed its business as the first son changed his name to run his wife's family business. His ambition to lead a bigger brewery with longer history led his own family deciding to terminate its business. His life is characterized by sake as he was born in a brewery family, studied brewery and married his wife through sake. He and his wife have a 13-year- 
old son who is already under training for brewing sake to continue the family business. The young sake master Hidoshi has dedicated himself to developing and manufacturing quality new sake with his passion and creativity.

\subsection{Storytelling as a marketing strategy}

\subsubsection{Storytelling}

Storytelling is the most natural form of communication from the beginning of human history (Patterson and Brown 2005). Simply put, storytelling can be said "telling a story", but not only in a verbal form. Storytelling refers to a communication means that takes various forms depending on the medium. Storytelling in a printed form can be a novel and storytelling in screen becomes a movie or a soap opera. In short, storytelling is a fundamental way for humans to perceive the world and a device for emotional utterance regarding the world as people see it (Kim and Jeong 2010). Storytelling is defined as to "share knowledge or experience through a story and episode to deliver a complicated idea, concept, and casual relation" (Sole and Wilson 1999). Storytelling can be an effective way retain existing customers as well as to attract potential customers (Jensen 1999; Delgadillo and Esealas 2004). In addition, it can even become a new business model (Montoro-Sanchez 2009).

All stories in storytelling can identify people and create emotional fellowship (Herskovitz and Crystal 2010). Studies on the development of a brand indicate the importance of developing a compelling story as one element of the brand icon (Boje 1995; Holt 2003; Woodside et al. 2008). Studies on the storytelling of wine argue that storytelling can differentiate a product from others in a competitive market, strengthening the identity of the product, create value, and have an influence on the price and image of the product (Mora and Moscarola 2012; Pierre and Florine 2013). These studies also argued that storytelling helps people get familiar with a product.

\subsubsection{Effects of storytelling}

Storytelling is valuable in that history of cultural heritage can be spread through it and thus historical facts can be experienced in the reproduction of the past environment. March (1995) explained the value of storytelling, especially the experience one gets which can influence the person's behavior.

We feel closer to people who frequently listen to our stories. Elis and Brewster (1991) stated that the effect of storytelling is to make storytellers exercise their imagination and develop creativity and make listeners empathize with characters in the story and immerse into the story by making an effort to interpret stories and illustrations. According to Kolumbus (1979), storytelling boosts people's confidence, excites their imagination and gives a sense of emotional satisfaction. 


\subsubsection{Marketing a product through storytelling}

Identifying a story to tell means having an attractive story that people would be interested in listening to. The initial stage of story identification is to make a list of stories related to a certain place. Stories can be classified into those related to culture, nature, industry, and the facility (Bae 2006; Wi and Park 2011). Among them, stories related to culture are very symbolic. From the traditional perspective, cultural stories are composed of myth, legend, and folklore.

A myth is a story where activities of sacred beings are recognized. Legend means a fictitious and secular story of a person under a special circumstance. Recently, however, manipulated myths or parallel myths have emerged with the decline of traditional concept of myth (Hong 2007). Description in a myth or a story is the reporting of more than one event delivered by more than one narrator. Stories unfold in various forms to deliver the core elements of the story. A storyteller and a listener share the same experience through the same event and subject, and the message of the story becomes real. An event in the story should be something special which is different from daily routines. In this regard, a myth can be regarded as a story that is worth delivering.

The next process is to find a representative story, which is the most suitable among those on the list, and to explore the best way to deliver it. A representative story encompasses a landscape and geography that are visible, where unique activities are available only at the place with certain symbolic values. In a case where the place is well-known through mass media, the contents can be used as a representative story. If there is no special story to deliver, new stories can be created. The next step is to identify the theme of the place. Theme is a symbolic system that represents the place that can stimulate a visitor's emotion to understand or remember the place. Various ways of delivering the story can be developed only after the theme is determined. The theme is composed of the flow of time, specific subjects, daily routines of the place, etc. (Korea Tourism Organization 2006).

What is important in experiencing a story is to provide a specific entity organized under the theme. Experiencing a story involves providing the visitors with an experience and environment for information. In this process, visitors can feel the place by experiencing the story and symbolic image of the place through participation. Lee (2005) stated that the establishment of symbolic places including buildings, structure, and space as a landmark.

Sharing a story is related to the development of feelings about the place. Morgan and Prichard (2004) also suggested that a place becomes popularized through the sharing of experience among visitors. Sharing a story is the process of active exchanges between host-created contents and guest-created contents. A representative way of sharing a story is a community created voluntarily by visitors. In the community, visitors to the same place share their experiences. Most of their activities are conducted online and the community takes the form of club activity service provided by a major portal.

Another type of sharing a story is a community created and promoted by a marketing organization including the local government. Usually, the marketing organization provides a space to create an online community or listens to the 
opinions of visitors through a survey. Sharing a story can be done through mutual communication between a local entity or residents and visitors. A local entity usually produces promotional material or operates a website to provide information on the place.

\section{Case analysis}

\subsection{Story of Kida Brewery}

The nine types of sake produced by Kida Brewery include Ginjo, Junmai, Rihe, Hathkoi, Tokubetsu Junmai, and winter special products. Rihe is Junmai Ginjo with $20 \%$ of alcohol, which is rare in Japan. Generally sake has 15 to $16 \%$ alcohol content. Making sake with $20 \%$ alcohol is very difficult. The sake master selects yeast with special properties and a longer starter fermentation period and controlled temperature. Thanks to this innovative process, $20 \%$ alcohol content Ginjo sake was born to attract new customers who prefer a higher level of alcohol like Soju (a Korean drink) or Whisky.

Hathkoi, which means first love, is intended to break the prejudice that sake is only for the old generation. To attract young customers, this sake has low alcohol content and looks fresh, attracting university students or females. It tastes like nonalcoholic beverage and it is in a 300-ml small white bottle with a pink label.

There are other stories related to brand name. For 80 years, Ukiboshi (Star of Snow), Kashiwara Musume (Daughter of Kashiwara Temple), and Miyokiku (Clean Chrysanthemum) had been produced and sold. When a daughter of 7th Kida master died of diphtheria about 70 years ago, the master decided to stop producing Ukiboshi (Star of Snow) and Kashiwara Musume as these brands symbolized his daughter. After that, Kida Brewery focused on making Hakuju, Yamato, Yamatono Kaori, Askagawa, and Miyokiku. Among them Miyokiku became the representative sake of Kida Brewery. Miyokiku comes from the Japanese literature and was included in a song written by a monk. Currently, there are two high-end Dai Ginjo products made by Kida Brewery: Hakuju (white wine) and Koju (yellow wine). White wine is presented as 白寿, meaning 99 years of age. The number 100 is 百 and 白 means 99 as it does not have a stroke on the top. In addition, Koju is described as 皇酒 and means 111 years of age with the following formula: 白 $99+-+++-=111$. As such every single meaning and story hidden in sake brand makes people immersed in finding deeper meanings and more stories.

Hakuju and Koju are sold at three to four times higher in price than the general grade sake but the products made every year are in short supply. In particular, only 50 bottles of Koju are produced a year and sold only by order. The reason for this small production volume of Koju can be found in the manufacturing method. Koju is a luxury sake product which uses Yamada Nishiki, special rice dedicated to making sake with the polishing rate of $35 \%$. The unique characteristic of Koju is found in the last squeezing phase (called Shibori).

In general, after the squeezing phase of liquor, constant pressure is maintained in a huge tank containing fermented rice. In the case of Koju, however, thick sake is 
put into large fabric bags and hung. This process is called Hukuro Shibori. One or two drops of sake would drop from the large bag at a time and these drops are gathered into a ceramic bottle called "a dove" which has a narrow neck and wide body. The first few drops from the bag are called Arabashiri and the interim process is called Nakadori and the final process is called Seme. Sake extracted only by natural force has a clearer and deeper taste than by other methods. The sake made in the interim process called Nakadori is exhibited at the National New Alcohol Contest, conducted annually by the Hiroshima Alcohol Research Center. The Koju brand has won this contest many times, making it a popular New Year's Holiday gift sold in Japanese luxury department stores.

Kida Brewery is located near Kashiwara Jingu (shrine) in Nara Prefecture. Kashiwara Jingu was established in 1899 and one of the 17 shrines recognized in Japan. This shrine honors the first Japanese emperor (Jimu). Kashiwara Jingu uses a great quantity of sake every year for rituals and ceremonies, including the New Year's greetings. Kida Brewery receives rice called Hinohikari from Kashiwara Jingu and offers 300 bottles of $1.8 \mathrm{~L}$ sake every year. In early February when the last Shibori process is underway, Kannushi of Kashiwara Jingu (director of the shrine) visits the brewery to hold a congratulatory ceremony. This ceremony is to wish for good sake production without any problem as its products will be used in the ceremonies at the shrine.

As explained earlier, the 8th Sake master of Kida Brewery had no son but two daughters and was determined to have his first daughter continue his family business when she was 16 . At first, she was not interested in taking over the family business responsibility. One day when her elementary school teacher asked Mr. Kazuyoshi to visit his daughter's school, he saw his daughter's diary with a drawing. The diary and the picture in it showed her willingness to become a sake master and continue her family tradition. Unlike other high school students who made money from working part-time jobs, she helped her father with shipping sake. She entered a university dedicated to alcohol making to study more about sake brewing. After graduation, she got her first job at the Dakara Brewery, a large firm, to learn and experience more about making and distributing sake. When she was in training at the Tokyo Alcohol Test Research Institute to become a sake expert, she met her husband Mr. Kida Hidoshi. As Kida Brewery has the family house and sake production plant contained in one location, she could balance her life as a mother and businesswomen (dealing with accounting, tax, import and export, customer relationship management, delivery, etc.). In the environment where her grandparents and parents have kept their family business based on dedication and cooperation, she naturally learned how to strike a balance between work and family. This case shows that continuing family business of sake brewery is not the business for only man.

There are two types of sake masters in Japanese breweries. One is the sake master (called "Toji") with skills and the other is the one who succeeds his or her family business. Sake masters running the family business run their business by making close relationship with Toji. Running the brewery business, including sales, marketing and promotion, falls under the responsibility of masters who run a family business and production of sake falls under the responsibility of Toji. The 9th Kida 
master, Hidoshi, performs both roles: making and selling sake. Of course there are Toji masters working for him but Mr. Hidoshi leads all processes of making sake, as well as running the family business. Most sake masters are seniors with long years of training and experience, usually in their late 70 or 80 s. They make sake based on their experience and skills including rice washing, mixing time in the brewing process, fermenting process, the amount of rice wine starter to use, and frequency of planting yeast, etc. However, Mr. Hidoshi has reduced the chance of failure by adding statistical data to his experience.

In the sake master's research lab, a daily processes are charted in a graph in the database. The annual plan is established so that the sake making process can be seen at a glance. This approach has made the brewing process very systematic at Kita Brewey. In addition, daily data is inputted into the computer. The same method is applied to making sake every year, but taste is evaluated mathematically. In addition, continuous efforts are made to make better quality products that taste better. About 40 complex processes are involved in sake making but the basic manufacturing process can be summarized as shown in Fig. 1.

Quality of sake is determined by water, rice, technology, and wind. Among them water and rice are the most important elements as ingredients of alcohol. About $80 \%$ of alcohol is made of water so water is the major determinant for the quality of sake. Water, which amounts 20-30 times of rice used, is required for making sake. Sake masters use water that flows from mountains, streams or rivers. However, sake masters at the Kida Brewery of Nara Prefecture must use underground water as there is no river or mountain nearby. Thus, they had a deep well dug at home to secure water for sake. Water in the well shows the least temperature change with only 1-2 degrees higher or lower than annual average temperature. The water in the well contains minerals as the water comes through various channels. However, the well water may contain iron, so Kida Brewery has a dual filtering system. The brewery prepares water suitable for sake by removing iron, organic matters, pigments, ammonia, chrome, etc., using a charcoal filter system (active carbon).

The well water contains such ingredients as potassium, phosphoric acid, magnesium, calcium, and sodium. Potassium, phosphoric acid, and magnesium are important ingredients for growing sake starter and yeast. Lack of these ingredients would delay the growth of yeast and sake starter, thus resulting in a bad taste. The technology of preparing the water with the most suitable ingredients is the secret of Toji. The second important factor is rice. Nara prefecture produces the best quality rice for sake in Japan. The region has rivers, mountains and the plain in harmony. The prefecture is known as the place of god. That is the reason why Nara prefecture was the old imperial city and has led the Japanese culture.

About 30 years ago, a special type of rice dedicated to high-end sake began to be produced. This dedicated rice for sake has been improved for easy polishing. As a result, the rice has a round shape compared to general rice, and also big and hard to prevent the rice from being broken during polishing. Compared to general rice, it has less moisture that is suitable for making high-end sake. The rice dedicated to sake is produced at the foothills of the mountain where water drains well when it rains rather than produced in regular rice paddies that contain a pool of water. 


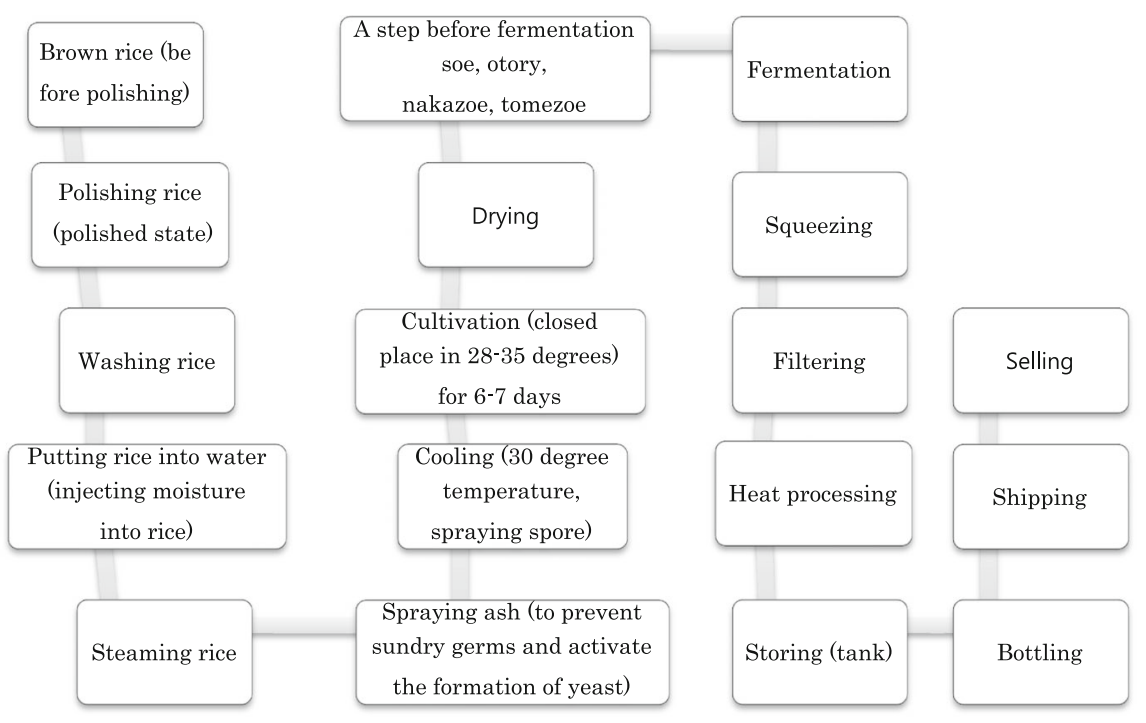

Fig. 1 The manufacturing process of sake

High-end sake uses deeply polished rice. The lower the usage rate of rice, the higher the degree of polishing.

\section{Results}

\subsection{Storytelling strategy of Kida Brewery}

In general, sake distribution goes through the wholesaler, retailer and eventually to the consumer. The sales structure of Kida Brewery showed that wholesalers account for $10 \%$, retailers $55 \%$ and direct sales to general consumers $35 \%$. Recently, the share of direct sales to general consumers has increased, primarily due to the development of the Internet and tourism development. General consumers living in the vicinity of Nara Prefecture visit the brewery, after obtaining relevant information online, to taste and buy sake at the brewery shop.

In addition, Nara Prefecture is a well-known historical and cultural tourist destination as it was the capital of Japan. The increased number of tourists visiting Japanese breweries is primarily due to designating 2010 as the year that marks "1300 Years of Nara Prefecture as Capital of Japan". Kida Brewery took this as an opportunity to attract visitors and promote its products. To expand its customer equity (Roofthooft 2010), Kida Brewery is providing the following programs to visitors. 
1. Visitors can touch, watch, and compare different types of rice and the polishing process.

Differentiation and reliability of rice, the most important ingredient of sake, are emphasized. The kind of rice used by Kida Brewery is 1.5 times bigger than general rice. Seedling space should be wider than that of general rice as the rice plant is easy to be blown down by wind. With a wide space between rice plants, the plants grow shorter and thicker, and can withstand strong wind. In addition, the rice is grown organically without using fertilizer or pesticide. Natural enemies are used to prevent harmful insects. A harmful insect, called Danishira that harms the rice plant, is countered by natural enemies like small shrimp, sparrow, and bat. As such, Kida Brewery produces sake made of organic rice by establishing an ecosystem based on long-time research and development.

2. Visitors can watch rice-washing, steaming and fermentation processes.

In general, a sieve or net is used to scoop up rice when washing. However, fine residue on the water surface becomes attached to the rice when the rice is drawn from the water. To remove this fine residue, the brewery developed an automatic washer that makes this fine-residue overflow. With this machine, it is possible to wash rice clean while preventing breakage through friction. In addition, this machine has a time control function to accurately control the moisture content in rice.

Steaming rice influences the taste of sake significantly. When rice is steamed in bulk, it sticks to the side and the bottom of the steamer, and the state of steamed rice differs according to the heat transition amount. Therefore, the artificial rice made of plastic should be put into a bag and the bag should cover the bottom to make rice steamed evenly.

3. Visitors can taste various brands and pour sake into empty bottles.

Kida Brewery makes various kinds of sake products. Visitors can taste these products in the brewery. In addition, a customer can select the sake he likes and pour necessary amount into a bottle and then purchase it. The customer can even put a private label on the bottle. It is customized sake, which is the preferred way of purchasing sake for gift.

4. In the museum, visitors can experience the history and tradition of Kida Brewery.

Kida Brewery has 300 years of history. The brewery has kept traditional tools and facilities (Fig. 2). Visitors can experience the traditional process of making sake. By touching and feeling the wisdom of ancestors, visitors can experience the actual taste of sake in a historic place.

\subsection{Ways to improve storytelling as a promotion strategy}

\section{(1) Brand storytelling}

Each region of Japan can form a task force dedicated to the development of sake brand storytelling, dealing with identifying and upgrading history, processes, characteristics of ingredients, technological features and characteristics of brand so 

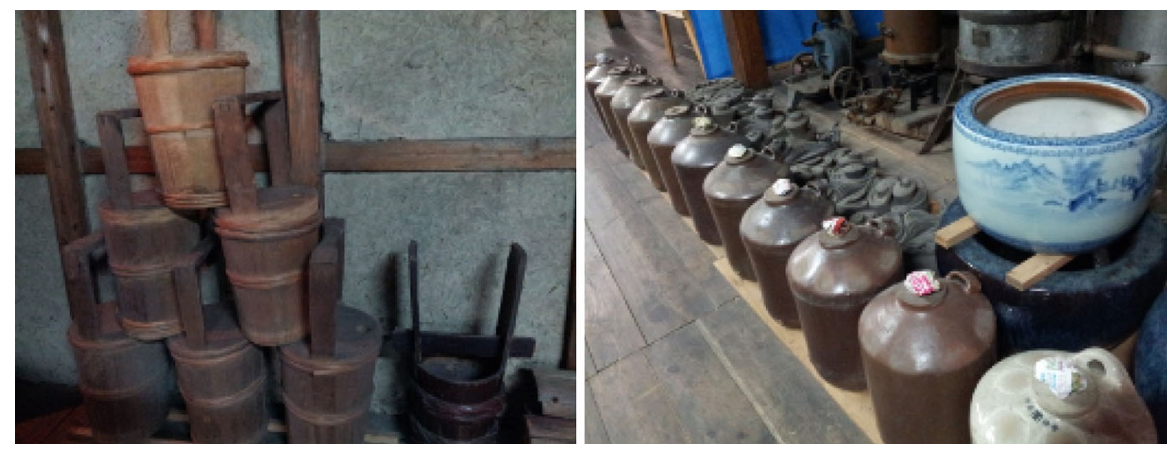

Fig. 2 Traditional tools used at Kida Brewery

that the information can become a marketing tool for tourism (Jimenez-Zarco et al. 2011). Contents of storytelling should be linked with success factors of tourism. In addition, cooperation with the sake brewery association of each region, universities, NGOs, local governments, and commissions on traditional culture is important to establish local brands of sake as tourism attractions.

\section{(2) Development of an experimental program for storytelling}

There are many regions in Japan with sake museums or sake tasting places. These places can be utilized as a venue where visitors can learn about the history of sake making, development of different types of rice, as well as tasting different sake products. In addition, a sake village can be established so that visitors can see differences in regional products.

It is suggested to establish food museums and traditional event pavilions to introduce the culture and history of Japanese food along with sake. This approach can promote the history, uniqueness and tradition of sake business. These facilities can serve as attractive tourist destinations, especially for foreign visitors. "Shushinkwan" located in Kobe organizes a special event by opening an old building of a brewery as a concert hall where customers can enjoy music along with sake and dining. The event is very popular among customers.

\section{(3) Globalization of sake through storytelling}

Humorous stories related to food, touching stories that involve traditional drinks, or folklore should be collected and used as cultural contents.

A systematic approach to expose the story of sake to the outside world is required for its globalization. One way of globalizing sake is to organize a special event with world's famous wine sommeliers and sake sommeliers, harmonizing Japanese culture with sake. Stories related to sake are various as each region has different sake. Therefore, it is important to attach interesting stories to each sake product. It is also proposed to hold a contest where foreign sake lovers evaluate sake products from their own perspectives in a global sake fest. 
(4) Online and offline branding

A new approach to sake storytelling can utilize online promotions and social network services. Taking advantage of various promotion strategies that can spread across the online medium, the image of sake can be presented as a noble cultural drink. Bloggers and Tweeters can provide many stories of their experiences winning trust from other customers. In addition, appealing to the emotion of customers can be done offline by providing various experiences of sake making and tasting. Recently, it was found that the storytelling of tourism by power bloggers had a significant impact on customers' motivation for tourism. It seems that the same approach can be used online as a way to deliver deep information about the tradition of sake.

\section{Conclusion}

\subsection{Summary and implications}

This study examined the issue of revitalizing the sake brewery industry in Japan through storytelling. The case selected for this study is Kida Brewery located in Nara Prefecture. This research examined the tradition of sake making by Toji, who laid the foundation for the globalization of sake, with their indomitable craftsmanship. This study is based on a qualitative case study. This study found that Kida Brewery can reinvent the sake industry using a marketing strategy based on storytelling of Kida Brewery's 300 years of history and tradition. This study also explored innovative ways to win trust from customers by utilizing the brewery's facility as part of experience for tourism. In addition, it provides a new strategy and opportunity related to global marketing in response to challenges of the master culture and family business.

\subsection{Limitation and future research needs}

The scope of this study is limited as it focused on a case study of Kida Brewery. Thus, a general theoretical discussion of storytelling as a marketing strategy was not attempted. The future research should explore the success factors of the sake storytelling strategy by conducting an empirical study of a large enough sample of sake breweries in Japan. The storytelling strategy can be used as a way to market sake on the global stage that can generate benefits in a greater scale. What should be noted is that storytelling method should be responsive to the changes in the global market that include ever increasing customer demand and expectations.

In Japan, the concept of craftsmanship, technology, and succession of family business is called "Shinise". The sake industry is in the first place among the top 10 Shinise industries created before the Edo ear in Japan. Nevertheless, the global market environment provides many new challenges to the Japanese sake industry. First, is it possible for the sake industry to withstand fierce grobal competition-based solely on its tradition and family business? Second, is it possible for the Japanese 
sake industry to continue running its business only with the capability of the second or third generation family entrepreneur in the environment where CEOs must develop strategies to meet the challenges of the global market? Third, how can the sake industry keep up the value of traditional sake in competition with other alcoholic beverages that pursue mass production using modern technologies? Fourth, how can the sake industry recruit talented young people to preserve traditional technology in a family business envermment while respond to changing customer tastes?

The future research should address these questions. The 8th sake master of Kida Brewery told his son-in-law, who is the 9th sake master, "I hope that you will always remain as a sake master who keeps the family tradition rather than you become a business man who turns 295 years old Kida Brewery into just a company". Kida Brewery is dedicated to providing quality sake products to its customers based on the integrity of its long tradition.

Open Access This article is distributed under the terms of the Creative Commons Attribution License which permits any use, distribution, and reproduction in any medium, provided the original author(s) and the source are credited.

\section{References}

Bae YD (2006) History and significance of production and consumption of Andong Soju. Local Hist Local Cult 9(2):375-413

Boje DM (1995) Stories of the storytelling organization: a postmodern analysis of Disney as "TamaraLand". Acad Manag J 38(4):997-1035

Delgadillo Y, Esealas JE (2004) Narrative word-of-mouth communication: exploring memory and attitude effects of consumer storytelling. Adv Consum Res 31(1):186-192

Elis G, Brewster J (1991) The storytelling handbook for primary teachers. Penguin Books, New York

Herskovitz S, Crystal M (2010) The essential brand persona: storytelling and branding. J Bus Strateg 31 (3): $21-28$

Holt DB (2003) What becomes an icon most? Harv Bus Rev 81(3):43-49

Hong SG (2007) Restoring history and culture of Han River through storytelling. Seoul Development Institute

Jensen R (1999) Dream society: how the coming shift from information to imagination will transform your business. J Consum Policy 20:289-323

Jimenez-Zarco AI, Martinez-Ruiz MP, Izquierdo-Yusta A (2011) Key service innovation drivers in the tourism sector: empirical evidence and managerial implications. Serv Bus 5(4):339-360

Kim MJ (2010) Effects of ethnocentrism and receptivity to other cultures affecting Preference for traditional alcohol drinks: focusing on Makgeolli and Sake. Food Serv Manag 13(4):7-31

Kim MH, Jeong HG (2010) The study on development of local dishes in Chungcheongnam-do through storytelling: centered on King Muryeong and King Tamra and Mongyudowonbangbap. J Korea Soc Food Cult 25(3):213-232

Kim S, Yoon B (2012) Developing a process of concept generation for new product-service efforts and its influences on service recovery performance. Serv Bus 6(3):323-348

Kolumbus ES (1979) Is it tomorrow yet? Handbook for education of the very young. MCTC, Haifa

Korea Agro-Fisheries \& Food Trade Corporation (2006) All about brands of agricultural products (Kwon $\mathrm{HC}$ et al.)

Korea Tourism Organization (2006) Glowing tourism storytelling

Lee JH (2005) Establishing a conceptual model of tourism development based on symbolic image and cultural activities of venues. J Korea Assoc Reg Geogr 23(2):93-113

Lee SJ (2011) The study on the impact of purchasing propensity and understanding of consumers using sake restaurant on their satisfaction and performance of restaurants. Thesis at Sogang University 
March C (1995) The art of storytelling. Neriwether Publishing, Colorado

Montoro-Sanchez A (2009) Competitive dynamics and business models in service business: a promising research subject. Serv Bus 3(4):311-318

Mora P, Moscarola J (2012) Representations of the emotions associated with a wine purchasing or consumption experience. Int J Consumer Stud 34:674-683

Morgan N, Prichard A (2004) Meeting the destination branding challenge. In: Morgan N, Pride R (eds) Destination branding: creating the unique destination, 2nd edn. Elsevier Butterworth-Heinemann, Oxford, pp 59-78

Patterson A, Brown S (2005) No tale, no sale: a novel approach to marketing communication. Mark Rev 5 (4):315-328

Pierre M, Florine L (2013) Does storytelling add value to fine Bordeaux wine? Wine Econ Policy 2:3-10

Pulizzi J (2012) The rise of storytelling as the new marketing. Publ Res Q 28(2):116-123

Roofthooft W (2010) Customer equity: a creative tool for SMEs in the services industry. Serv Bus 4 (1):37-48

Satoshi K (2013) Reading sake: alcoholic drink brewed with rice, water, yeast, and human (trans: Lee Y). Sigma Books, Seoul

Sole D, Wilson D (1999) Storytelling in organizations: the power and traps of using stories to share knowledge in organizations. Train Dev 53:44-52

Wi T S, Park JW (2011) Brands of agricultural products: promise with customers. Rural Development Administration Interrobang, 31

Woodside AG, Sood S, Miller KE (2008) When consumers and brands talk: storytelling theory and research in psychology and marketing. Psychol Mark 25(2):97-145 